\title{
Itinerario de la novela modernista española
}

\section{The Itinerary of the Spanish Modernist Novel}

\author{
Juan Antonio Garrido Ardila \\ University of Edinburgh
}

\section{RESUMEN}

Este artículo ofrece una panorámica de la novela española del periodo modernista y trata de explicar los modos en que algunas obras españolas de esa época reflejan los principales elementos de la novela modernista europea. Se observa cómo a finales del siglo XIX una serie de novelas escritas por autores realistas ensayan la interiorización psicológica propia de la novela modernista. Se presta especial atención a Insolación de Pardo Bazán, Su único hijo de Clarín y a Nazarín de Galdós. Luego de observar las innovaciones de Ganivet, el artículo se centra en las novelas de forma y fondo modernistas publicadas por Baroja, Azorín y, muy especialmente, Unamuno. De esta suerte se proyecta una panorámica comprehensiva de la novela española de esa época.

Palabras Clave: novela modernista, Pardo Bazán, Galdós, Clarín, Unamuno, Baroja, Azorín.

\begin{abstract}
This article examines the development of the Spanish novel during the Modernist period and identifies the main features of European Modernist writing in some Spanish novels. This piece notes towards the end of the $19^{\text {th }}$ Century a series of novels written by Realists developed an interest in psychology and inward perspectivism. Special attention is paid to Pardo Bazán's $I n$ solación, Clarín's Su único hijo and Galdós's Nazarín. After noting Gavinet's innovations, the article focuses on novels written by Azorín, Baroja and Unamuno to complete a comprehensive view of the Spanish novel written during the Modernist period.
\end{abstract}

Key words: Modernist Novel, Galdós, Pardo Bazán, Clarín, Unamuno, Baroja, Azorín.

No hace mucho reflexionaba Donald Shaw en torno a cómo la filología española aún porfía en rechazar el término modernismo a pesar de valerse asiduamente de la denominación postmodernismo. Shaw (2010: 909) no se resigna a las medias tintas y moteja el reconocimiento del postmodernismo y el recelo ante el Modernismo de paradójico $^{1}$. En efecto, en España se ha venido reconociendo el modernismo de la poesía de gentes como los Machado, Villaespesa y

\footnotetext{
${ }^{1}$ También se denuncia esta paradoja en C. Christopher Soufas (2010: 8).
} 
Marquina o de la prosa simbolista de Valle-Inclán, al tiempo que a Juan Ramón Jiménez se le ha encumbrado como cúspide del Modernismo español ${ }^{2}$. Desde antiguo, la novela española de aquellos años ha quedado encuadrada dentro del Noventayochismo, y muy a pesar de los esfuerzos de muchos — desde Ricardo Gullón (1969) hasta Germán Gullón $(2006)^{3}$ — por contextualizar debidamente a los noventayochistas en la corriente modernista, persiste entre los especialistas en literatura española una empecinada remisión a emplear la expresión novela modernista. Cierto es asimismo que, desde los años ochenta, se ha proclamado, siquiera muy esporádicamente y casi como predicando en el desierto, la naturaleza modernista de ciertas novelas ${ }^{4}$, y que en los últimos años se han redoblado estos esfuerzos ${ }^{5}$. En los setenta, el Modernismo se convirtió en una de las bogas predominantes entre los investigadores de filologías otras a la hispánica. En el momento presente, cuando el resto de las filologías se esmera por resaltar el carácter transnacional de esta corriente literaria, a la filología española le es forzoso reconocer que las muchas novelas españolas escritas en el periodo (aproximado) comprendido entre 1890 y 1940 participan de la misma estética que las novelas modernistas del resto de Europa. No se trata de importar nociones extrañas, ni de capitular a terminologías foráneas, sino de reconocer que en España se escribió novela de rango modernista que merece un lugar destacado en la literatura europea.

En este trabajo me propongo esbozar una panorámica general de la novela modernista en España, centrándome en los principales literatos y en sus obras más representativas. Pretendo retrotraerme (a la estela y a inspiración de Germán Gullón $)^{6}$ a antes de la primera década del siglo XX para así observar en la última

\footnotetext{
${ }^{2}$ Véase, por ejemplo, Ricardo Gullón (1971).

${ }^{3}$ En el ámbito actual del estudio de la novela del periodo que nos ocupa se prescinde de la etiqueta noventayochista, pero se considera la novela como producto eminentemente patrio. Como se sabe, no es parca la bibliografía en torno a la contemplación del denominado Noventayocho en un contexto cultural más amplio; al respecto véanse, por ejemplo, los números monográficos sobre el tema publicados por Ínsula en 1998: El 98, a nueva luz, Ínsula, 623 (1998) y La regeneración literaria del 98, Ínsula (1998). Asimismo los volúmenes de la Historia de la literatura española de Crítica: Celio Alonso (2010) y José-Carlos Mainer (2010). Además de otros como: Richard A. Cardwell y B. McGuirk (1993), Iris Zavala (1991), Dolores Romero López (1998), Alan Hoyle (2000).

${ }^{4}$ Germán Gullón (2003), John Macklin (1983 y 1993), C. A. Longhurst (1992 y 1977) y J. A. G. Ardila (2012b).

${ }^{5}$ Fundamentalmente Nil Santiáñez (2002 y 2004), Mary Bretz (2001) y Christopher Soufas (2007).

${ }^{6}$ En su estudio de título El jardín interior de la burguesía. La novela moderna en España (1885-1902) (2003, primera edición de 1991), Germán Gullón ha estudiado el desarrollo de las técnicas de narración introspectiva desde Fortunata y Jacinta y La Regenta, a Los trabajos del infatigable creador Pío Cid y Paz en la guerra, hasta las cuatro novelas de 1902. De esta suerte, Gullón analizó los estadios literarios que culminaron en la catálisis de la novela modernista española, del que investigadores posteriores hemos, en toda justicia, de declararnos deudores.
} 
década del Diecinueve el germen del Modernismo y resaltar aquellas características de la novela española que reproducen las de la novela modernista europea. Esto mismo han hecho, en relación a algunas obras concretas, algunos críticos que aquí se irán mentando. Incido en que mi objetivo presente estriba en poner ante el lector, en panorámica diacrónica, el trabamiento de obras que se sucede desde las primeras novelas de regusto modernista hasta las magna opera del Modernismo. Si bien, por motivos de espacio, este trabajo habrá de procurar la concisión, trataré de ofrecer un itinerario comprehensivo y en todo lo posible completo que resalte las hechuras y el valor de la novela modernista española. Me centraré aquí en los principales exponentes, desde las novelas de anticipación modernista escritas por Benito Pérez Galdós, Emilia Pardo Bazán y Clarín, a Ángel Ganivet y Juan Bautista Amorós, hasta llegar a las principales obras de estética puramente modernista de Pío Baroja, Azorín y Miguel de Unamuno, con un sucinto comentario de Ramón del Valle-Inclán, cuyas afinidades con el Modernismo son tan notorias como reconocidas. Entiendo que estos autores representan el núcleo más representativo y también de mayor mérito estético del Modernismo español en su variante novelesca, por lo que no habré de extenderme hacia la obra de autores posteriores como Ramón Pérez de Ayala y Gabriel Miró o de la vanguardia ${ }^{7}$.

Al igual que la crítica especializada en la novela modernista europea, adopto la denominación modernista para referirme a las novelas que difieren sustantivamente y trascienden el Realismo-Naturalismo y que comparten una serie determinada de características. Naturalmente, nos enfrentamos al problema de la definición de qué es el Modernismo y qué atributos definen una novela modernista. Entiendo aquí, sucintamente, que la novela modernista pretende irrefutable e incontestablemente transcender (o, cuando menos, superar o renovar) la novela realista-naturalista y se caracteriza esencialmente por:

1. su conciencia estética e innovadora (que reclamaron Arthur Rimbaud al proclamar «Il faut être absolutement moderne!» y Ezra Pound con su máxima «Make it new») y

2. su perspectiva interiorizadora, que se vale de técnicas introspectivas en

a. la narración (v.g. en la subjetivación antipositivista de la realidad [que suele dar en la autoficción], en el pluriperspectivismo, en la ralentización y fragmentación de las tramas, en el empleo asiduo de digresiones) y

b. el desarrollo psicológico de los personajes (mediante una fijación en lo interior, v.g. en el uso del monólogo interior, y en los estados de semiconsciencia y de subconsciencia, v.g. en el uso del flujo de conciencia, los sueños y la duermevela) ${ }^{8}$.

\footnotetext{
${ }^{7}$ Sobre las mujeres novelistas véase Roberta Johnson (2003); sobre las mujeres, en general, en el modernismo español, Susan Kirkpatrick (2003) y Roberta Johnson (2010).

${ }^{8}$ En ello recojo la síntesis de las principales taxonomías de la novela modernista, como se explica en numerosos estudios, entre los que cabe destacar Malcolm Bradbury y James
} 
Todo ello se aprecia en las novelas de Henry James - tales que The Ambassadors (1902), The Wings of the Dove (1903) y The Golden Bowl (1904)y, con anterioridad, en las de Knut Hamsun — Sult (1890) y Mysterier (1892) entre otras - mucho antes de las obras de los considerados maestros modernistas, como por ejemplo James Joyce, Virginia Woolf, Thomas Mann, Robert Musil y D. H. Lawrence.

Ha sido moneda de uso corriente, entre los críticos, recurrir al año 1902 para fechar el inicio de una nueva época en la literatura española. Así, JoséCarlos Mainer (1986; véase también Spires 1988) propuso que se considere y reconozca el periodo que abarca desde 1902 hasta 1939 como la Edad de Plata de la literatura española, pues en esas décadas escribieron algunos de los mejores literatos españoles. El año 1902 se hinche de significación porque en él se publicaron cuatro novelas de importancia capital: Amor y pedagogía de Unamuno, Camino de perfección de Baroja, La voluntad de Azorín y la Sonata de otoño de Valle-Inclán. Cada una de estas se distingue claramente de las novelas realistas decimonónicas y, al formar conjunto, todas ellas constatan inescrutablemente el cambio de aires en la narrativa española9. Esos aires modernistas los habían agitado Pardo Bazán y Clarín allá por 1889-90 y ululaban bravíos a finales del decenio. Sin embargo, el reemplazo de la novela realista por la modernista no se obró de la noche a la mañana. El año 1902 constata que una nueva forma de novelar había echado hondas raíces en España, pero en la última década del siglo XIX la novela española no disimulaba sus pujos modernistas. Al igual que August Strindberg en Suecia, Henrik Ibsen en Noruega o Henry James en Estados Unidos, en España algunos escritores que brillaron excelsamente en el Realismo-Naturalismo introdujeron en sus obras de finales de siglo elementos puramente modernistas. Aunque no se pueda hablar de cambios radicales como los del sueco y el estadounidense, es claro que los más afamados novelistas del Realismo español proyectaron en sus mismas obras una visión ambigua de la realidad e incidieron en las honduras psicológicas de sus personajes, características estas que descubren un cambio de tercio en las actitudes de la literatura. Esto es así en los casos de Benito Pérez Galdós, Emilia Pardo Bazán y Clarín. Pardo Bazán escribió estudios de literatura europea como La revolución y la novela en Rusia (1887) y La literatura francesa moderna $(1910)^{10}$. Su ensayo más conocido quizá sea La cuestión palpitante (1883), donde disertaba en torno a la novela

McFarlane (1991). Iguales características se reconocen en estudios posteriores como Jesse Matz (2008) o David James (2010). En el caso español remito nuevamente a los ensayos de Nil Santiáñez (2003: 247-280) y Germán Gullón (2003: 33-41).

${ }^{9}$ Sobre la relevancia de estas cuatro novelas véanse, por ejemplo, Francisco José Martínez Martínez (2003) y el monográfico VV. AA. Lecturas de 1902: perspectivas y contrastes de Ínsula, DCXXV (2002), así como Gullón (2003: 139-216).

${ }^{10}$ Sobre el conocimiento que Pardo Bazán tuvo de Francia y de la literatura francesa véase María Isabel Jiménez Morales (2008). 
naturalista. En 1889 publicó Insolación y en 1890 Una cristiana y La prue$b a$, en las que se percibe un cambio de tono y estética, hacia un claro simbolismo y espiritualismo, que se continúa en su producción posterior. La profundidad psicológica de los personajes de Pardo Bazán se acentúa progresivamente a partir de entonces ${ }^{11}$.

En Insolación hallamos ya, en 1889, una perspectiva narrativa virada con decisión hacia el interior de los personajes (Mayoral, 1987; Santiáñez, 1989). La novela comienza relatada por un narrador que, al final del primer capítulo, anuncia que cederá la palabra a la misma protagonista, en lo que califica de relato «mental» $(74)^{12}$, que se extiende hasta el capítulo IX incluido. De esta suerte, Pardo Bazán deja a un lado la voz del narrador para acometer una incursión al interior de la mente. Logra, así, establecer tres perspectivas que proceden de la realidad exterior objetiva a una realidad interior subjetivada: 1) la narración de hechos exteriores por parte del narrador, 2) la narración de esos mismos hechos exteriores por la protagonista, y 3) los pensamientos interiores de la protagonista. En el texto comprendido entre los capítulos II y IX, ambos inclusive, se reproducen los pensamientos interiores de la protagonista y, allí, pueden hallarse instancias de monólogo interior ${ }^{13}$. Véase, por ejemplo, el tercer párrafo del capítulo IX, donde se inicia un monólogo interior que se prolonga y extiende hasta el final de ese capítulo. Aquí se hallan los atributos esenciales de los monólogos interiores: discurso en el interior del pensamiento, dirigido al mismo emisor y que no es interrumpido por el narrador.

A la largo de la novela volverá Pardo Bazán a emplear esta técnica de interiorización hasta convertirla en seña de identidad de Insolación. Ejemplo - entre otros muchos - de ello lo hallamos cuando la protagonista declara: «Ya que estoy dialogando con mi alma y nada ha de ocultarse [...]» (93), y, más adelante:«me encuentro a solas con mi conciencia» (133). En su empleo persistente de técnicas de narración introspectiva, Insolación constituye un claro precedente español de la novela modernista. Pardo Bazán logró, de ese modo, abrir la senda que alejaría la novela española del realismo-naturalismo para llevarla hasta el Modernismo.

En 1890 publica Clarín, Su único hijo, donde se perciben innovaciones sustantivas con respecto a sus anteriores creaciones novelescas ${ }^{14}$. Las innovaciones estéticas de Su único hijo propiciaron que esta obra se tuviese durante

${ }^{11}$ Sobre Una cristiana y La prueba véase el análisis de Nil Santiáñez (2003: 279 et passim).

${ }^{12}$ Las sucesivas notas a Insolación procederán de la edición de 2011 de Cátedra.

${ }^{13}$ Sobre el desarrollo del monólogo interior en Insolación, Su único hijo y La incógnita y Nazarín véase Ardila (2013b). En ese trabajo elaboro una definición del monólogo interior, sobre las existentes.

${ }^{14}$ Sobre el espiritualismo en Su único hijo véase Juan Oleza (1988 y 1989). Adviértase, no obstante, que Germán Gullón (2003: 85-100) ha observado una renovación estética en La Regenta que apunta claramente hacia el Modernismo. 
buena parte del siglo XX como una anomalía en la trayectoria de la novela española: al tiempo que urde una estructura sumamente compleja, se esmera Clarín por descender a las simas de la psicología humana, con obsesión propia de su idolatrado Dostoievski. Los críticos que pretendieron y pretenden entender Su único hijo como producto de la mentalidad naturalista no pueden por menos que motejarla de caprichosa rareza. Antes al contrario, Su único hijo se desmarca inconfundiblemente de la estética y los presupuestos realistas-naturalistas para internarse en los dominios de la narrativa de esencias modernistas. En la última de las novelas de Clarín arraigan aceradamente tres características fundamentales de la novela modernista: la mitificación romantizada del héroe, el empleo de estados de soñolencia y la perspectiva interiorista.

Se ha presentado al protagonista de Su único hijo, de nombre Bonifacio, como un «héroe decadente» (Valis, 1981) ${ }^{15}$. Bonifacio se cree un héroe a la manera de los modelos literarios románticos. El protagonista de esta novela, refiere el narrador, «a ratos, se tenía por un héroe, por un hombre digno de figurar en una novela en calidad de protagonista» $(220)^{16}$. Las interpretaciones respecto de la presentación del Romanticismo que Clarín ensaya pueden oscilar entre considerar esta novela un canto a favor del Romanticismo que precedió al Naturalismo, o tenerla por una sutil parodia de las conductas hiperbólicas de la literatura romántica. En un tiempo en que el Naturalismo decaía en Europa, resulta muy probable que Clarín cargase las tintas contra la estética naturalista que proscribía todo aquello que oliese a idealismo romántico. Ello se me parece especialmente significativo porque parte de la crítica entiende que el Modernismo surge y arraiga como un retorno a la mentalidad del Romanticismo y halla en Dostoievski y en Kierkegaard a sus tempranos precursores ${ }^{17}$.

Ciertamente, Clarín replantea — con mayor o menor intención irónicaalgunos valores de la época romántica. En una trama que combina las manidas relaciones adúlteras tan recurridas en la prosa naturalista, en que tanto el marido como la esposa mantienen relaciones extramaritales, donde incluso el anhelado hijo parece ser fruto de la relación adúltera de la esposa, las ilusiones y el idealismo la impregnan de un tenue, mas patente, halo romántico. En esta concertación, el sueño se convierte en un recurrido recurso, en el marco del idealismo. Así, se describe a Emma como una joven de «ojos soñadores» (162) obnubilada románticamente por un antepasado suyo. Se enamora des-

${ }^{15}$ Sobre el héroe decadente en la literatura española véase el capítulo «El héroe decadente» en Nil Santiáñez (2003: 169-206).

16 Todas las citas de $\mathrm{Su}$ único hijo provienen de la edición de 2009 de Cátedra.

17 Allan Bullock (1991: 68): «In literature ... the modern movement has roots in Baudelaire, Flaubert and Dostoyevsky, as indeed in Nietzsche, Ibsen and the twentieth century's own discovery, Kierkegaard who died in 1855». 
pués de Bonifacio; pero, una vez contraído matrimonio, afirma el narrador que «no era aquél el Bonifacio con que [Emma] había soñado» (161). A Bonifacio se le califica de «soñador soñoliento» (163). La idea del sueño en sentido de idealización se repite en varios momentos (v.g., 290-291; 342).

La visión introspectiva domina todo lo largo y ancho de Su único hijo, donde el subconsciente desplaza por sistema la percepción del mundo exterior. Aun cuando la introspección narrativa en Su único hijo haya sido escasamente estudiada, en este texto aparecen claros conatos de monólogos interiores. Se alude a una «frase interior» (239), a «la voz de la tentación» (250), a «una voz de la conciencia que le gritó en el cerebro» (430) y a una «voz secreta» (439). A esta sazón, en ocasiones varias se ensayan monólogos interiores, que el narrador califica de «soliloquios» (409). A veces estos conatos los aborta la intervención del narrador, en otras nos hallamos ante ejemplos de monólogos interiores (v.g. en 340-341). En definitiva, en Su único hijo hallamos una novela, publicada en 1890, donde se emplean con sobrado acierto numerosos elementos propios de la novela modernista. Su único hijo se planta soberbiamente en los aledaños de la estética modernista y mediante ella marca Clarín, con golpe de voz firme y contundente, la dirección hacia el Modernismo de la narrativa española posterior a él. Las innovaciones de $S u$ único hijo se ponen de manifiesto al contraste con obras posteriores, sobre todo con Niebla: en Bonifacio, en sus ensoñaciones y sus barruntos ontológicos y discreteos sentimentales, hállase, por ejemplo, el precedente más inmediato de Augusto Pérez.

Junto a Clarín, la trayectoria literaria de Galdós presenta una progresión estética de especial interés, que le llevó de ocupar la cima de la novela realista española a escribir novelas ornamentadas con lustrosos ribetes modernistas (cf. Gullón 2003: 74). Gullón ha señalado el «desarrollo interno» (2003: 68) y la «forma psicológica» (2003: 69) que hacen de Fortunata y Jacinta una obra que se asoma a la novela introspectiva, además de los conatos de monólogo interior en La desheredada (2007: 35-43) ${ }^{18}$. Las novelas de Galdós en que más claramente puede percibirse este giro quizá sean La incógnita (1890), Realidad (1890), Tristana (1892), Nazarín (1895) y Misericordia (1897). La incógnita es una obra esencialmente experimental ${ }^{19}$, en la que Galdós ensaya la interiorización psicológica de los personajes. Como expresa Manolo Infante, en la carta XLI, en esta novela procura mostrar «la cara interna de los hechos humanos» (véase Correa, 1977: 152). Vistas en su conjunto, La incógnita y Realidad revelan asimismo un esfuerzo consciente por moldear las formas de la novela mediante incursiones en otros géneros: si La incógnita es novela

${ }^{18}$ Gullón señála (2007: 39) acerca de La desheredada: «Galdós alcanza la suma novedad [...] en el uso del monólogo interior y de la segunda persona narrativa».

${ }^{19}$ Al respecto véase Nil Santiáñez (1996). En otro lugar (2003: 380), Santiáñez resalta de La incógnita su «radical modernismo». 
epistolar, Realidad comienza como novela dialogada y acaba como versión teatral. (Baroja adoptaría también la forma dialogada en La casa de Aizgorri). La experimentación con las formas narrativas revela la tendencia de la novela hacia una estética nueva.

En Nazarín se observan con lupa las dos caras de una misma verdad. El pluriperspectivismo es un rasgo definidor de la narrativa modernista: el narrador realista presenta una verdad objetiva y sujeta a la fenomenología; el modernista observa la realidad subjetivamente, sin aceptar imposiciones empiristas y siempre experimentándola en sensaciones interiores. El narrador de Nazarín presenta la novela como la investigación sobre la persona del sacerdote Nazario, donde se pone por escrito la verdad y se erradican las versiones impuestas verbalmente por unos y otros. Al concebir dos personajes encargados de investigar la vida de este religioso, Galdós ofrece una perspectiva dual que facilita la ambigüedad y que constituye una diferencia clara con respecto al narrador único y omnisciente de la novela realista. El resultado final es una novela cuyo personaje se viste de una ambigüedad perenne que permite diversas interpretaciones del problema planteado al principio: la verdad de Nazario. De este modo, la narración, que pretendía imponer una verdad única, acaba por reconocer que la realidad se halla sujeta a interpretaciones muy varias (véase Kronik, 1974: 93). Nazarín se cuenta, pues, como uno de los ejemplos de novela galdosiana en que la narrativa propende hacia el espiritualismo (cf. López, 1978) y que refleja ecos de la profundidad psicológica de Dostoievski (Palley, 1968: 3). Nazarín certifica la transición estética en la trayectoria novelística de Galdós, quien fuera el principal exponente de la novela realista. A partir de 1895 se distingue ya la progresión de la novela española en pos de oteros muy alejados de las formas narrativas realistas. En 1897 publica Galdós Misericordia, obra que Longhurst (1999; 2000a) ha escogido como representativa de la transfiguración de la narrativa de Galdós y ejemplo del alborear de la novela modernista española. En esta novela se perciben características de la novela realista tales como la minuciosa descripción de la realidad exterior y de los ambientes sociales. Repárese sobre todo en que la construcción de mundos paralelos donde los personajes anhelan la realización de sus sueños e ilusiones que se da en Misericordia es, en su esencia, igual que la que se lee en Svarmere (1904) de Hamsun.

Lo que la crítica ha calificado, en referencia a las respectivas obras de Clarín, Galdós y también Pardo Bazán, como etapas espiritualistas representa el principio de la novela modernista española. La última década del siglo XIX presenta un corpus de novelas claramente escoradas hacia las coordenadas de la narrativa modernista. En ese decenio experimenta la novela española un proceso de transición que progresa de la novela realista dominadora antes de 1890 a la novela modernista definida meridianamente ya en 1902. Después de Pardo Bazán, Clarín y Galdós, Ganivet continuó esas tendencias como por lex naturalis. 
En los años ochenta Juan Bautista Amorós (cuyas obras publicó como Silverio Lanza) había escrito algunas novelas imposibles de clasificar dentro de las tendencias realistas. Amorós publicó, entre otras novelas, Mala cuna y mala fosa (1883) y Noticias biográficas del Excmo. Sr. Marqués del Martillo (1889). Si bien resultaría en todo punto arriesgado calificar las obras de Amorós de modernistas, cabe recordar cómo en dos artículos Baroja lo calificaba de inclasificable y, consecuentemente, subversivo con el Naturalismo ${ }^{20}$. En la segunda mitad de los noventa, Ángel Ganivet, escritor jovencísimo y desvinculado del Realismo, sacó a la luz algunas obras de estética muy dispar a la realista-naturalista. Aunque a Ganivet se le conoce sobre todo por su ensayo histórico Idearium español, escribió asimismo (además de teatro y poesía) dos novelas: La conquista del reino maya por el último conquistador español Pío Cid (1896) y Los trabajos del infatigable creador Pío Cid (1898).

El protagonista de La conquista acomete el sometimiento de un reino ultramarino. Ganivet ensaya un análisis de uno de los temas más candentes de la época: el imperialismo. Aunque España, en 1896, se hallaba en ciernes de perder sus últimas colonias, las grandes potencias europeas vivían un periodo de esplendor colonial, realidad que Ganivet pudo asimilar de primera mano durante su estancia en Amberes. Se trata, pues, de una temática de proyección europea, que Baroja retomaría después en su novela dialogada Paradox, rey (1906). Los trabajos del infatigable creador Pío Cid se ha granjeado los encomios sinceros de algunos críticos que la han presentado como un texto clave en el arraigamiento del Modernismo en España ${ }^{21}$. Es muy posible que Ganivet se inspirase en el pensamiento de Ibsen al concebir la idea de Los trabajos. En Los trabajos, Pío Cid acomete la labor ibseniana de cambiar la sociedad mediante la educación de cada uno de sus individuos, proceso este que Ibsen había plasmado genialmente en Rosmersholm (1886). En Los trabajos se percibe claramente una diferenciación con respecto a las novelas realistas. Nos hallamos ante un texto que, en rigor, carece de la trama definida linealmente de las novelas realistas: la anécdota — que Ganivet utiliza con sutileza magistral en sus ensayos - substituye a la descripción exhaustiva y a la diégesis trazada en línea recta, y el protagonista impone un punto de vista profundamente subjetivo, tanto que los más de los críticos (v.g., Herrero, 1966; Salgado, 1997) han querido ver en Pío Cid el yo lírico de Ganivet. La palmaria identificación del personaje con el autor —que resplandece nítida en sus relaciones amorosas y en los principios sociales que mantiene- confiere a esta novela categoría de autoficción y, en este respecto, la convierte en pionera de la narrativa del siglo XX. El punto de vista subjetivo permite la interiorización, de modo más o menos asiduo, en la psicología del protagonista. Gani-

\footnotetext{
${ }^{20}$ Se ha referido ampliamente a los artículos de Baroja, C. A. Longhurst (2000b: 28-29).

${ }^{21}$ Principalmente Germán Gullón (2003: 121-137), Nil Santiáñez-Tió (1994); Raúl Fernández Sánchez-Alarcos (1995); Laura Rivkin (1986), Theodore Alan Sackett (2001).
} 
vet tenía plena consciencia de que se adentraba en un territorio nuevo y así lo manifiesta en varias alturas de la novela. En este respecto, el principio de Los trabajos no deja lugar a dudas: el narrador confiesa ser un novelista primerizo y haber resuelto utilizar a Pío «en una novela de psicología al uso» ${ }^{22}$ (65). Por«novelas psicológicas al uso» debía de referirse, entonces, a las antedichas de Pardo Bazán y Clarín, además, naturalmente, las de su idolatrado Hamsun. La que quizá sea la más clarividente declaración de intenciones literarias de cuantas Ganivet inserta en su novela se halla en el trabajo $\mathrm{V}$, en el pasaje en que Pío acude a la «asamblea literaria» de la fuente del Avellano. Departen los tertulianos en torno a las letras después de la lectura de cierta narración de uno de ellos. Cuando el narrador afirma la necesidad de una literatura de «reparación social» (368), Pío le corrige: «Esa idea [...] la has tomado de los autores positivistas, que son una plaga más temible que la langosta» (368) y proclama a renglón seguido: «Mejor que la observación de la vida es la acción sobre la vida. La acción exterior y casi mecánica en las obras de arte nos parece ya ridícula [...] Lo bello sería obrar sobre el espíritu de los hombres» (369). Los trabajos merece tenerse por una obra típica de la literatura europea de los últimos años del siglo XIX, por una novela de apariencia esencialmente modernista. La arenga literaria de Pío Cid en la fuente del Avellano reconocía la preeminencia de la narración introspectiva y declaraba la guerra a la novela naturalista de fundamentos positivistas. Con Los trabajos, el diplomático granadino, esgrimiendo su pluma en el otro extremo de Europa, inmerso en los paisajes nórdicos, había tendido a España el más elocuente y meridiano de los manifiestos modernistas, en forma de ejemplo — el autor que pretende escribir una novela psicológica- y de teoría articulada en labios del protagonista.

Con estos precedentes, los cuatro autores de las respectivas novelas de 1902 irrumpen estruendosamente en la escena literaria del cambio de siglo. Todos ellos habían publicado narrativa antes de 1902. Baroja publicó Camino de perfección en 1901 por entregas antes de su salida como libro en 1902. Antes aparecieron las novelas La casa de Aizgorri (1900) y Aventuras, inventos y mixtificaciones de Silvestre Paradox (1901), además de la colección de relatos breves Vidas sombrías (1900), en la cual se perciben también muchas de las temáticas y cuestiones tratadas posteriormente. La casa de Aizgorri acomete un tema científico de moda: el determinismo. Como teoría filosófica, el determinismo había sido rebatido contundentemente por Henri Bergson en Essai sur les dones immédiates de la conscience (1889). Baroja fue un antideterminista cuya obra, de ordinario, gira en torno a cuestiones irracionales que se resisten a aproximaciones positivistas. Esta novela tiene por protagonista a los Aizgorri, que desde hace tres generaciones viven del negocio familiar de una destilería. El padre declara sufrir una suerte de demencia he-

${ }^{22}$ Todas las referencias a Los trabajos provienen de la edición de Cátedra (1998). 
reditaria, opinión ratificada por el médico de la familia. Así lo estima también Águeda, la hija, quien acabará por creer que ha perdido la razón. Habrá de ser el pretendiente de Águeda quien proclame que no existe tal enfermedad y que la trágica angustia de los Aizgorri la ha obrado la imaginación. Baroja reacciona de modo inequívoco contra el determinismo: el médico ha errado en el diagnóstico y la ciencia ha fracasado estrepitosamente. Importa señalar el claro componente romántico de esta obra: el título y la temática recuerdan The Fall of the House of Usher de Poe. Los aires románticos hacen de La casa de Aizgorri un ejemplo de novela modernista de vertiente romántica.

En 1901 publicó Baroja la novela Aventuras, inventos y mixtificaciones de Silvestre Paradox. Las apreciaciones críticas sobre esta obra se han centrado eminentemente en su calidad de parodia de la novela folletinesca y también en su descripción de la sociedad española de la época (véase Moral, 1974). Además de ello, en Silvestre Paradox Baroja vuelve a satirizar las ciencias positivas y deterministas. El protagonista epónimo es un inventor versado en ciencias, que acumula objetos con el propósito de encontrarles un uso. El mismo título es ya significativo: la novela tratará las mixtificaciones del protagonista, a quien Baroja apellida Paradox y describe al principio como «Individuo esencialmente paradoxal» $(48)^{23}$ cuya tarjeta de visita lee «Sylvestris Paradoxus del Orden de los primates» (47). En su conjunto, y además de la parodia del folletín y los reflejos de la vida madrileña de principios de siglo, se percibe ubicuo en Silvestre Paradox un irónico desdén por la ciencia y los científicos, por lo que debe entenderse como otra reacción barojiana contra el positivismo y la novela realista. Paradox reaparece en la producción novelística de Baroja en Paradox, rey, novela dialogada que tiene como temática la colonización de África. Esta novela se explica como la reflexión de Baroja ante la euforia colonizadora de que fue testigo durante una estancia en París en 1899, euforia que contrastaba con el pesimismo de España tras la derrota en Cuba. En Paradox, rey el naufragio de un navío arroja a los supervivientes a la costa africana, donde se proponen establecer un nuevo régimen. La temática recuerda poderosamente La conquista de Ganivet y, como la novela de Ganivet, la de Baroja rezuma una evidente sátira contra las potencias colonizadoras. Paradox, rey vuelve al ambiente antirrealista de La casa de Aizgorri en cuanto que la característica más innovadora estriba en la narración que se desprende de los prejuicios de la lógica empirista propia de la novela realista.

Camino de perfección se serializó en el diario La Opinión a lo largo de 1901. Algunos críticos han presentado esta novela como ejemplo de un modernismo perfectamente definido (cf. Garrido Ardila 2013a; Germán Gullón 2006). Al igual que Los trabajos de Ganivet, en Camino de perfección late

${ }^{23}$ Las referencias de Aventuras, inventos y mixtificaciones de Silvestre Paradox proceden de la edición de 1999 de Espasa-Calpe. 
la preocupación por la decadencia de España. Las técnicas narrativas hacen alarde de superar ya los preceptos del Realismo. Se trata de una novela donde Baroja, a edad tan temprana, demuestra un depurado dominio en el uso de técnicas simbolistas. De Camino de perfección cabe destacar las descripciones simbolistas del paisaje. Según discurre la acción, el narrador ilustra el pesimismo y la melancolía del protagonista por medio de brevísimas descripciones del paisaje, por lo general del cielo. Los cielos barojianos en Camino de perfección exultan una soberbia belleza: en tal solo una o dos frases, Baroja pinta un celaje de hermosísimas tonalidades melancólicas, como un pintor impresionista que con dos trazos de su pincel delimita un visión arcana en la distancia. Esta técnica de sutil insinuación contrasta poderosamente con las pormenorizadas descripciones del realismo-naturalismo. Al contrario de las novelas realistas, donde la trama transcurre diligentemente, Baroja gusta de parar el tiempo. De tal suerte que en Camino de perfección toda acción se acompaña de la meditación en la cual la acción se detiene y desaparece para ceder el protagonismo a la reflexión interior.

Camino de perfección comporta asimismo un mensaje filosófico acorde con el ideario modernista ${ }^{24}$. Al igual que en La casa de Aizgorri, en la novela de 1902 adopta Baroja una posición claramente antipositivista e irracionalista. El protagonista, Fernando Ossorio, es un joven estudiante de medicina en Madrid que pronto queda desencantado de la ciencia y abandona sus estudios para dedicarse al arte. En las primeras páginas de la novela se describe uno de los cuadros de Fernando: Horas de silencio muestra a unos jóvenes hermanos, vestidos de riguroso negro, de rostros pálidos, en un cuarto desde el que se distingue, a través de la ventana, una gran urbe, con sus chimeneas; el narrador destaca la tristeza de los rostros, de lo que deduce que ha acontecido una desgracia. Este cuadro refleja a la perfección la angustia del fin de siglo ante el progreso: la gran ciudad es «el monstruo que había de tragar a los hermanos abandonados»(12-13). Desde el principio de la novela, el protagonista siente esta angustia pesimista que se expresa de cuando en cuando y de modo inequívoco. El último párrafo del capítulo 20 presenta una clara muestra de esta actitud en los pensamientos del protagonista y también de la interiorización en la perspectiva vital: «¿Qué es la vida? ¿Qué es vivir? ¿Moverse, ver, o el movimiento anímico que produce el sentir? Indudablemente es esto: una huella en el alma, una estela en el espíritu [...] Además, el mundo de afuera no existe; tiene la realidad que yo le quiero dar. Y, sin embargo, iqué vida esta más asquerosa!» (121). La cuestión de la voluntad ausente en Fernando responde a la filosofía de Schopenhauer: Fernando abandona la depravada Madrid en busca de la perfección, que quizá halle al final del relato. En definitiva, Camino de perfección presenta ya una estética y una filosofía en perfecta consonancia con el Modernismo.

\footnotetext{
${ }^{24}$ Sobre la filosofía en la novela de ese periodo véase Roberta Johnson (1993).
} 
Azorín publicó su primera novela, títulada Diario de un enfermo, en 1901. Gran éxito alcanzó La voluntad, publicada en 1902. Como el resto de las novelas de 1902, La voluntad plantea una concepción radicalmente distinta de la novela como género, tanto que, cuando se publicó, los críticos cuestionaron que pudiese denominarse novela. La voluntad sigue las experiencias del joven Antonio Azorín, a quien puede tomarse como el yo lírico del autor. Antonio mantiene una estrecha amistad con Yuste, su maestro y con quien mantiene numerosas conversaciones en torno a cuestiones filosóficas y literarias. Antonio ejemplifica el héroe decadente, mucho más, quizá, que Pío Cid y Fernando Ossorio. En el capítulo 5, Antonio expresa toda su desesperación ante la vida: «Hoy me siento triste, deprimido, mansamente desesperado» (2008: 333), lamenta antes de mencionar a Schopenhauer y sus teorías sobre la voluntad. Toda la novela despliega una sesuda reflexión en clave schopenhaueriana sobre la aciaga existencia en la sociedad moderna. Pero, además de ello, Azorín implanta en las letras españolas la autoficción (adelantada por Ganivet), donde personaje y autor se funden en uno.

Aparte de su profundidad filosófica, La voluntad presenta una serie de innovaciones estructurales. En una conversación, Yuste diserta en torno al género de la novela y pone voz a las teorías del autor sobre la misma: califica a Baroja como el mejor de los nuevos novelistas y establece como principio de la novela la ausencia de trama. Ello propicia que en la novela se acumulen más y más comentarios a modo de reflexiones digresivas que fragmentan el curso de la diégesis. Esta sucesión de diálogos y monólogos en ausencia de la trama produce un texto donde predomina la interiorización y donde el pensamiento y lo interior suplanta a la fábula. En definitiva, se trata de una novela muy distinta a las novelas realistas y que, en función de esas características, merece calificarse de modernista. La siguiente de las novelas azorinianas fue la titulada Antonio Azorín (1903), donde se reproduce la principal característica formal de La voluntad: la meditación impuesta a la acción y a la trama. Antonio Azorín refiere las experiencias del epónimo protagonista y sus sentimientos por Pepita. En la ausencia, Antonio escribe a Pepita cartas en las cuales el lector puede vislumbrar el amor. Pero nunca declara Antonio este amor explícitamente: este argumento —el incipiente amor de Antonio y Pepita - se prolonga sin concretarse y realizarse, haciendo que la trama quede ahogada por la meditación. En esas cartas, especialmente, expresa el protagonista la melancolía extrema que ya plasmó en La voluntad, por ejemplo: «Pepita, Pepita: yo me siento conmovido y estoy a punto de sollozar ... Yo me veo solo, yo me veo triste; yo veo que mi juventud va pasando estérilmente, sin una ternura, sin una caricia, sin un consuelo...» (1991: 224) escribe en una ocasión.

Las confesiones de un pequeño filósofo (1904) es la tercera y última de las novelas protagonizadas por el personaje Antonio Azorín. A partir de aquel año Martínez Ruiz adopta el sobrenombre de Azorín. Las confesiones de un 
pequeño filósofo comienzan con un apartado de título «Dónde escribí este libro», firmado «Azorín», en que se describe la casa donde tuvo lugar la redacción y sus alrededores. Sigue el apartado «Origen de este libro», firmado con las iniciales «J.M.R.», donde se explica cómo Azorín pretende presentarse a elecciones para diputado en Cortes y cómo sus amigos le han animado a escribir un libro en que exponga sus pensamientos más íntimos de modo autobiográfico. Lo que sigue es una novela lírica de una profundísima sensibilidad. La novela carece de trama, y en cada episodio se refiere una serie de pensamientos íntimos, algunos relacionados con la niñez y la familia del autor, otros en los que reflexiona melancólicamente. Las confesiones es una intensa y brillante novela digresiva ${ }^{25}$; el texto se concibe como una digresión a una situación extratextual: sus amigos le dicen que escriba un libro en lugar de entrar en la oratoria de las Cortes. De esta suerte, ese libro se construirá mediante el trabamiento de reflexiones personales. Aunque en los dos primeros apartados aparezcan las firmas de Azorín y de Martínez Ruiz, el autobiografismo latiente en las dos anteriores novelas se patentiza en Las confesiones. Azorín es ya Martínez Ruiz (o viceversa) y la novela es la novela de la vida y los sentimientos del autor. El lirismo alcanza cotas de hermosura arrobada, que dota todo el texto de un luctuoso aire de melancolía. Hermoso ejemplo de ello lo constituye el capítulo 40, titulado «Esas mujeres», emocionado llanto existencialista ante la azarosa existencia.

El lirismo y una escasa trama se afianzan en la producción novelística posterior de Azorín. Azorín retorna a la novela en la década de los veinte. Las cualidades modernistas de sus primeras novelas brillan con especial fuerza en Doña Inés (1925), Félix Vargas (1928) y Superrealismo (1929). Doña Inés sigue un hilo argumental: el enamoramiento de Inés con un poeta y cómo un encuentro de ellos ha sido entendido como un pequeño escándalo. La trama se limita a esto y queda oculta tras una mayoría de páginas dedicadas a descripciones de lirismo y emoción desbocados. El capítulo 4 presenta un excelente ejemplo de la paralización de la acción y el tiempo: Doña Inés deja que discurra el tiempo y el narrador indica: «No sucede nada; todo está tranquilo» (1973: 77). Azorín logra, en pasajes como este, superar la acción linear y la medición del tiempo de la novela realista para ahondar en el interior de los personajes. Félix Vargas presenta un esquema similar al que Unamuno había ensayado un año antes en Cómo se hace una novela: Félix, el protagonista, relata la concepción y la redacción de un libro. Superrealismo es una de las novelas surrealistas españolas por excelencia. En ambos textos Azorín incide una y otra vez en que la realidad que interesa a la literatura, al arte en general y al hombre es la realidad interior.

El lirismo vetea distintivamente las primeras novelas de Ramón del Va-

${ }^{25}$ Sobre la novela digresiva en España, y en Las confesiones, véase J. A. G. Ardila (2011b: 218-219). 
lle-Inclán, las cuatro novelas cortas protagonizadas por el marqués de Bradomín — tituladas Sonata de otoño (1902), Sonata de estío (1903), Sonata de primavera (1904) y Sonata de invierno (1905) - y otras novelas como Flor de santidad (1904). En Águila de blasón (1907) persiste este lirismo, pero a partir de 1908 las novelas de Valle-Inclán prescinden ya de la prosa poética. La técnica teatral del esperpento, cuajada en Luces de Bohemia (1920), pasó pronto a sus novelas ${ }^{26}$. Las primeras novelas de Valle-Inclán son novelas simbolistas, lo que les ha valido su inclusión en el canon modernista, que recientemente han sido objeto de un detallado estudio (Villanueva Prieto, 2005). Las sonatas se conciben como las memorias del anciano marqués de Bradomín. En cada una de estas novelas el narrador relata una aventura amorosa. Al marqués se le presenta en un epígrafe como un donjuán «feo, católico y sentimental». Con este personaje se parodia el mito del don Juan: Bradomín suele fracasar estrepitosamente en sus conquistas y, al contrario que don Juan, el marqués se enamora loca y desesperadamente en todas las ocasiones. Se trata de otra reacción contra la modernidad, donde los ideales románticos fracasan una y otra vez en una sociedad que no les da cabida. Las sonatas se construyen como una compleja relación de intertextos donde se parodian tradiciones literarias anteriores a la vez que se expresa una aguda sátira, de la que suele ser objeto la religión. Entre los muchos valores de las sonatas cabe destacar la calidad de su prosa lírica. La belleza de la prosa de Valle-Inclán recuerda a los simbolistas franceses y a los románticos, como al español Bécquer y los alemanes Hölderlin, en Hyperion (1797, 1799), y Heine, en Florentinische Nächte (1837).

Unamuno publicó su primera novela en 1897: una larga narrativa titulada Paz en la guerra, ambientada en la última guerra carlista del siglo XIX. En su primera obra, En torno al casticismo (1895), se percibe una evidente tendencia antipositivista (Garrido Ardila, 2009). De ordinario se presenta Paz en la guerra como una novela histórica, cercana al Realismo y algo distante de la estética novelística que Unamuno forjó en Amor y pedagogía. Antes bien, en la primera novela de Unamuno se perciben ya algunos elementos extraños al modo de novelar de los autores del Realismo: en Paz en la guerra los sueños y la perspectiva interiorista se asimilan a la realidad vivida por varios personajes. Los sueños caracterizan el idealismo de los personajes, por ejemplo cuando apunta el narrador que «aquello no era lo soñado» (299) ${ }^{27}$ y se refiere a lo que un personaje «soñó despierto» (300). Unamuno logra en esta novela plantear una realidad onírica al señalar que a Ignacio le parecía«el

\footnotetext{
${ }^{26}$ Adviértase que la estética del esperpento cabe perfectamente en la línea del teatro modernista de Strindberg, hasta el punto de que las características esenciales del esperpento se articulan ya en la Spöksonaten (1907) de Strindberg. Véase al respecto J. A. G. Ardila (2012c).

${ }^{27}$ Todas las referencias a Paz en la guerra provienen de la edición de 1999 de Cátedra.
} 
mundo un sueño» (305). Se adopta en la primera de las novelas de Unamuno una nítida perspectiva interiorizadora. Se invocan los fondos del espíritu (265) e incluso se lleva el mismo discurso narrativo al mundo interior de los personajes, o al recrearse imágenes desde la perspectiva interiorizadora: «Al siguiente día fuese a la orilla del mar, donde las olas se rompían en crestería de espuma, cantando la eterna monodia de su vida sencilla, y allí, como en un baño de calma, bajáronle los pensamientos de la víspera a reposar en el fondo fecundo del olvido» (447). Se reconoce asimismo «una voz interior» (177) e incluso menciona el narrador un «monólogo mental» (466) refiriéndose a lo que hoy denominamos monólogo interior. Por todo ello, aun cuando Paz en la guerra adopte técnicas narrativas propias del realismo, no es menos cierto que en esta novela se emplean recursos esenciales de la novela modernista, de los que Unamuno se valdría ulteriormente.

Su segunda novela, Amor y pedagogía (1902) muestra una forma radicalmente diferente de novelar. Avito Carrascal, el protagonista, es una suerte de sátira del sabio científico, como lo fuese Silvestre Paradox. En Amor y pedagogía, Avito Carrascal vive obsesionado por la ciencia. La parodia, rebosante de genialidad, se patentiza desde la misma descripción de Avito: «Vive Carrascal de sus rentas y ha llevado a la cima, a la chita callando, sin que nadie de ello se percate, un hercúleo trabajo, cual es el de enderezar con la reflexión todo instinto y hacer que sea en él todo científico. Anda por mecánica, digiere por química, y se hace cortar el traje por geometría descriptiva» $(59)^{28}$. La novela presenta un constante enfrentamiento entre las peripatéticas divagaciones de Avito y la desesperación de su esposa, Marina: él cree entender el mundo y la realidad merced a su perspectiva filosófica; ella, en sus juicios, muestra al lector de modo inconfundible la realidad que Avito no acierta a ver.

Unamuno se esmeró en Amor y pedagogía en desarrollar técnicas narrativas mediante las cuales lograse la interiorización de la realidad. Las principales de estas técnicas son el monólogo interior y el flujo de conciencia. En Amor y pedagogía se percibe un claro esfuerzo por emplear monólogos interiores y flujos de conciencia. Uno de los ejemplos mejor logrados del flujo de conciencia se pone en boca de Apolodoro, cuando meditando se dice: «¿Por qué caen las piedras, Apolodoro?, ¿por qué a mayor ángulo se opone mayor lado? ¡Apolodoro... boloro... boloriche...! ¡Apolo... bolo! ¡Ese Ramiro me las tiene que pagar...! Luis, Luis, mi Luis, Luisito... santificado sea tu nombre... no le digas nada, ¿has oído? ¿Por qué me llamará mamá Luis?... El oso hormiguero tiene la lengua así... ¡Pobre conejillo!, ¡pobre conejillo!» (109). Aquí discurre Apolodoro sobre cuestiones científicas como la gravedad o la geometría cuando a su mente acuden en flujo pensamientos en torno a la tragedia que vive: el mote boloriche que le han puesto sus compañeros de cole-

${ }^{28}$ Las referencias a Amor y pedagogía provienen de la edición de 2007 de Espasa-Calpe. 
gio, las trastadas de Ramiro, el modo en que lo llama su madre a espaldas de su padre, el conejo destinado a experimentos, que ha visto en un laboratorio y que sabe que está condenado a morir. Si bien de modo mucho más lacónico que las frases de mil palabras que James Joyce pone en boca de Molly en las últimas páginas del Ulysses, Unamuno en Amor y pedagogía nos ofrece estas muestras del flujo de conciencia, más de veinte años antes que Joyce, Proust o Woolf (cf. Garrido Ardila 2012a).

El reconocimiento del subconsciente es característica modernista que Unamuno introduce en su segunda novela. Ello lo logra mediante el flujo de conciencia pero también por medio de los estados de semiconsciencia. A lo largo de la novela hace referencia el narrador a un «demonio» o «demonio familiar», denominación mediante la cual designa a la voz de la conciencia. Por ejemplo, «Y una vez aceptado el concepto, acallando la voz del demonio familiar que le murmura: ¿Lo ves?, caíste, caíste y caerás cien veces’ prosigue pensando» (100). El «demonio» suele irrumpir en los pensamientos de Avito para advertirle de que ha cometido un error de interpretación. Estos errores se suelen producir cuando Avito discurre, equivocadamente y con prejuicios positivistas, acerca de la realidad.

A estos estados de semiconsciencia denomina Unamuno «sueño crónico», que no es más que soñar despierto. En las más de las ocasiones, Marina sucumbe a ese «sueño crónico» y en él discurren sus pensamientos, dejándose llevar por el subconsciente sin abstraerse totalmente de la realidad. Unamuno establece una clara diferenciación entre realidad, sueño crónico y sueño, categorías que se corresponden respectivamente con conciencia, semiconsciencia y subconsciencia. Es muy posible que, cuando Unamuno redactó Amor y pedagogía en 1901, conociese ya Die Traumdeutung (la interpretación de los sueños) de Freud, publicada en 1899 (con fecha de 1900). A veces Apolodoro duda de si vive o sueña, lo que dice el narrador que ocurre «desde que le hizo leer su padre una doctísima obra acerca del sueño, sus causas y sus leyes» (120). La única obra doctísima publicada antes de 1902 en que se relacionan los sueños con la realidad es La interpretación de los sueños ${ }^{29}$.

Mediante la exploración del subconsciente humano, Unamuno logra en esta novela, más que ningún autor español antes que él, la interiorización propia de la novela modernista. Amor y pedagogía es ya una novela puramente modernista. Sacada de su contexto literario y cultural — que es el Modernismo-, quizá se malinterpretasen los geniales logros de Unamuno y se tomasen por extravagancias. Unamuno quizá lo supiese y, por ello, antepuso a su novela un prólogo en el cual fingía ser un tercero. El prólogo comienza irónicamente: «Hay quien cree, y pudiera ser con fundamento, que esta obra es una lamentable, lamentabilísima equivocación del autor»(45), algo que solo

${ }^{29}$ Sobre el uso de los sueños en Amor y pedagogía y en Niebla véase Garrido Ardila (2012b). 
podrían creer quienes esperasen una novela sujeta a las convenciones de la novela realista.

Unamuno redactó su siguiente novela, de título Niebla, en torno a 1907, aunque no se publicó hasta 1914. En Niebla perfeccionó muchas de las técnicas que en Amor y pedagogía había ensayado. El resultado es una novela de la más alta calidad y con una contextura total y absolutamente modernista, en el más pleno sentido de la palabra. En Niebla plasma Unamuno buena parte de su pensamiento filosófico. En 1913 publicó Del sentimiento trágico de la vida, el más logrado de sus tratados filosóficos. Para Unamuno, el sentimiento trágico de la vida reside, groso modo, en la inminencia de la muerte y el entendimiento y superación de esta. La cuestión escatológica abarca cuantas cuestiones importan en la existencia. Unamuno aborda este problema en varias novelas: San Manuel Bueno, mártir trata la posibilidad de la vida eterna; La tía Tula, de la descendencia. En Niebla Unamuno presenta el amor que él llama espiritual, y que opone al carnal, como esencia de la existencia y modo de superación de la muerte (Garrido Ardila, 2008). Niebla está profundamente influenciada por el Forførerens Dagbog (1843) de Kierkegaard. Este influjo se percibe en múltiples aspectos temáticos del texto, pero así también en su mensaje filosófico. La idea de la niebla como metáfora de la existencia la toma Unamuno del Forførerens Dagbog, donde se describe la vida como «el reino de niebla y el mundo de sueños», concepción esta que Unamuno desarrolla en su novela (cf. Garrido Ardila, 2011c).

La interiorización domina el perspectivismo de Niebla. El 20 por ciento del texto lo componen las meditaciones de Augusto (Øveraas, 1993: 21), meditaciones plasmadas mediante monólogos interiores. En ellos Unamuno perfecciona notablemente la técnica del flujo de conciencia, lo cual se aprecia en dos aspectos fundamentales: los monólogos interiores no se limitan a párrafos, como era el caso de Amor y pedagogía, sino que alcanzan una extensión que incluso llega a ocupar todo un capítulo; mediante los monólogos interiores logra Unamuno dar mayor presencia a los estados de semiconsciencia. El mejor ejemplo de monólogo interior quizá se halle en el capítulo VII. Este capítulo se compone en su totalidad de una larga reflexión de Augusto acerca de la muerte, de la vida y del amor, y presenta el amor como lo único eterno en la vida. Uno de los muchos ejemplos de flujo de conciencia lo hallamos al principio del capítulo 4, cuando Augusto discurre en torno al amor y vienen a su pensamiento, desde la subconsciencia, recuerdos de momentos vividos en el pasado reciente. Esta notable diferencia en el uso que a los monólogos interiores y el flujo de conciencia que se da en Niebla con respecto a Amor y pedagogía se debe a la lectura de Sult (1890) de Knut Hamsun y el influjo que ejerció en Unamuno (cf. Garrido Ardila, 2012a).

También en Niebla perfecciona Unamuno el empleo de los sueños como experiencia complementaria a la realidad. Como en el caso de los estados de semiconsciencia en los monólogos interiores, los sueños en Niebla forman par- 
te de la historia y de la realidad que refiere. La innovación más llamativa de Niebla quizá la constituya su componente pirandélico - años antes de que este fuese empleado por Pirandello_- En Niebla se produce una relación, extensa, entre el autor y su protagonista, relación que forma parte de la trama y que contribuye a desarrollar el tema de la realidad —en Niebla se propone que la literatura es tan real como la realidad misma-. Esto lo consigue Unamuno algunos años antes que Pirandello en Sei personaggi in cerca d'autore (1921).

A Niebla se han atribuido influencias muy varias. La mayoría de los estudios se han centrado en las técnicas cervantinas desarrolladas por Unamuno (v.g., Vauthier, 1999). Entre las muchas atribuciones cervantinas que se le han reconocido, dos poseen una importancia capital en la construcción de Niebla — las voces narradoras y la percepción de la realidad- En Niebla hallamos un narrador infidente y también, en la terminología empleada por los cervantistas, un supernarrator, o narrador principal que se impone a otras voces narradoras (cf. Garrido Ardila, 2010). Mas lo verdaderamente importante es que Unamuno emplea más de una voz narrativa para dotar su relato de la subjetividad propia de las novelas modernistas. Cervantes concibió el Quijote como una parodia de la literatura idealista: en una época en que la narrativa prescindía del realismo, el Quijote presenta una historia sujeta al principio de verosimilitud. Unamuno realiza una parodia a la inversa: frente a la novela realista, que se fundamentaba en un estricto empirismo, Unamuno presenta una narración que desafía las versiones fenomenológicas de la realidad (cf. Friedman, 2006: 304). Al recurrir a Cervantes a fin de parodiar la percepción de la realidad impuesta por la novela realista, Unamuno emplea técnicas clásicas para construir un nuevo tipo de novela.

La mayor semejanza entre el Quijote y Niebla radica en que ambos autores emplean tradiciones literarias existentes para crear un nuevo tipo de novela. Niebla ostenta una gran conciencia creativa, en la cual Unamuno compone un nuevo tipo de novela a partir de las teorías de James y Freud, de la base filosófica (y, en gran medida, también temática) de Kierkegaard y de las técnicas de Cervantes. Niebla bien merece consideración de ser la novela más intertextual de la literatura española contemporánea. Esta intertextualidad no resta novedad e innovación a Niebla, sino que, por el contrario, la enrique$\mathrm{ce}^{30}$. En Niebla hallamos una novela pirandélica antes de Pirandello, onírica antes del surrealismo, y que emplea el flujo de conciencia antes que Joyce, Proust y que ningún otro escritor español. Unamuno demuestra en Niebla una decidida voluntad innovadora. Ello lo manifiesta Goti, cuando explica a Augusto que su novela es tan diferente a todo lo que se había escrito hasta la fecha que no será novela sino nivola y explica que la denominará así para que los críticos literarios que se aferran a las estéticas al uso no digan que no se

\footnotetext{
${ }^{30}$ Stan Smith (1994: 5-6) ha señalado cómo la novela modernista se nutre de elementos literarios precedentes.
} 
atiene a las normas del género novelístico. Niebla presenta, pues, todas las características de la novela modernista y merece tenerse como una de las obras capitales del Modernismo europeo.

Tras la publicación de Niebla, Unamuno continuó escribiendo novelas, muchas de las cuales se construyeron conforme a moldes modernistas. La tía Tula (1921) y San Manuel Bueno, mártir (1931) se conciben como textos de una extraordinaria ambigüedad, donde Unamuno presenta versiones muy distintas de la realidad. Tula es personaje de férreas convicciones y que domina la acción, reminiscente de las mujeres de Ibsen, como Hedda Gabler o Helene Alving. El papel de Getrudis resulta extremadamente ambiguo: el lector habrá de decidir si Gertrudis es una heroína que se entrega generosamente a su familia, o una déspota que les impone su voluntad. En igual tesitura se hallará el lector de San Manuel Bueno, mártir, la narración que Ángela hace de la vida de San Manuel. La narradora descubre aquí que el santo no creía en la vida eterna, lo que, sin embargo, parece contradecir al final del relato. San Manuel Bueno es una novela tremendamente ambigua, donde nada se dice explícitamente y todo debe leerse e interpretarse merced al contexto situacional de cada pasaje. Esta novela puede leerse de dos modos muy diferentes, según se interprete el contexto: puede ser la historia de la fe del santo, o puede ser la historia de amor en que Ángela amó a San Manuel y este, aunque también la amaba, renunció a ella (Garrido Ardila, 2011a). Cómo se hace una novela (1927) merece tenerse por la novela digresiva española por excelencia (véase Garrido Ardila, 2011b: 220-222). En Cómo se hace una novela Unamuno establece una digresión constante donde reflexiona en torno a cuestiones como la literatura, pero que se centran fundamentalmente en su vida. Unamuno escribió Cómo se hace una novela durante su exilio en Francia. Gran parte de los comentarios digresivos de esta novela tienen por objeto la situación política española y el perjuicio que Unamuno creía que el régimen de Primo de Rivera estaba causando a España. En definitiva, se trata de la novela más digresiva de la literatura española contemporánea.

En conclusión, la novela española produjo un importante corpus de obras que, en su estética, participan de las características de las mejores novelas modernistas del resto de Europa. Las novelas modernistas de los grandes autores españoles de principios del siglo XX deben entenderse como el resultado de un proceso paulatino de maduración. La última década del Diecinueve fue un tiempo abonado para que la narrativa española comenzase a demudar su coloración. En ese decenio entran de lleno en sus etapas espiritualistas Clarín, Galdós y Pardo Bazán. Lo que se ha denominado espiritualismo en estos autores de rango realista-naturalista no es más que la preponderancia en sus respectivas obras de las estéticas que se alejaban cada vez más del Realismo-Naturalismo y privilegiaban elementos propios del modernismo, especialmente la interiorización y el reconocimiento de una realidad fuera de lo empírico. Su único hijo es una novela muy otra a La Regenta en cuanto que 
entra de lleno en el interior de los personajes hasta llegar, en ocasiones, al subconsciente. La última de las novelas de Clarín se halla mucho más próxima al Modernismo que al Realismo-Naturalismo. En Nazarín Galdós acomete una exploración de la realidad muy otra al objetivismo de la ficción naturalista y que ya había ensayado en La incógnita. Con estos precedentes, Ganivet comenzó su trayectoria novelística comprometido con una estética nueva. La producción novelística de Unamuno se inicia en el terreno de la novela histórica, mas con una perspectiva que oscila entre la observación de la historia y la interiorización que explora la intimidad y a veces el subconsciente de sus personajes.

De esta suerte, se observa nítidamente una evolución de las formas novelísticas, desde el cambio de los grandes autores realistas hacia el espiritualismo de estética premodernista hasta las obras nuevas de Ganivet. En ello se reflejan en España las mismas inquietudes estéticas que afloraban por aquel entonces en otros países de Occidente. No en vano, la novela española de entre siglos no se desentiende de las corrientes literarias que recorrían Europa, como ejemplifican el interés de Pardo Bazán, Clarín y Galdós por la literatura francesa, la fascinación de Ganivet y Unamuno con la literatura escandinava o los aires de simbolismo francés de Valle-Inclán. Los autores del nuevo siglo, cuyo compromiso social con España han señalado desde antiguo los críticos, escribieron un considerable número de novelas de extraordinaria calidad. Concibieron sus novelas como una reacción contra el Realismo, y sus novelas antirrealistas reproducen las características propias de la novela modernista europea $^{31}$. De muy diversos modos, sus novelas fueron pioneras en uno u otro aspecto. Baroja destaca por sus técnicas descriptivas; Azorín, por su preocupación estética y formal de sus autoficciones; Valle-Inclán, por su prosa poética; Unamuno, por sus muchas innovaciones en la interiorización de las percepciones de la realidad. Todos ellos despuntan por la extraordinaria calidad y belleza de su prosa y por el profundo calado filosófico de sus novelas. El modernismo español produce novelas digresivas, novelas psicológicas, novelas filosóficas; en la novela modernista española se desarrollan técnicas como el monólogo interior y el flujo de conciencia. Por todo ello es imposible entender la novela española posterior (hasta la actualidad) sin entender antes la novela modernista. En su conjunto, España presenta una serie importante de novelas de estética modernista y entre todas ellas quizá merezca destacarse Niebla, novela innovadora, de profundo significado filosófico, de prosa depurada y genial, y de lectura amena.

\footnotetext{
${ }^{31}$ Debe recordarse aquí la proliferación de artículos y ensayos sobre el género de la novela que publicaron los autores e intelectuales de aquel tiempo. Los más conocidos son las $\mathrm{Me}$ ditaciones del Quijote (1914) e Ideas sobre la novela (1925) de Ortega y la contestación que les dio Baroja en el «Prólogo casi doctrinal sobre la novela» en La nave de los locos (1925). Amén de los comentarios metaficcionales en las novelas de Unamuno y Azorín.
} 


\section{BIBLIOGRAFÍA CITADA}

Alonso, Celio, ed. (2010). Hacia una literatura nacional 1800-1900. Barcelona: Crítica.

Azorín (1973). Doña Inés (Historia de amor). Madrid: Castalia.

Azorín (1991). Antonio Azorín. Madrid: Cátedra.

Azorín (2001). Félix Vargas y Superrealismo. Madrid: Cátedra.

Azorín (2007). Las confesiones de un pequeño filósofo. Madrid: Espasa-Calpe.

Azorín (2008). La voluntad. Madrid: Cátedra.

Baroja, Pío (1999). Aventuras, inventos y mixtificaciones de Silvestre Paradox. Madrid: Espasa-Calpe.

Baroja, Pío (2004). Camino de perfección. Madrid: Alianza.

Baroja, Pío (2011). La nave de los locos. Madrid: Cátedra.

Bradbury, Malcolm y James McFarlane, eds. (1991). Modernism. A Guide to European Literature, 1890-1930. Londres: Penguin.

Bretz, Mary (2001). Encounters Across Borders. The Changing Visions of Spanish Modernism, 1890-1930. Lewisburg: Bucknell University Press.

Bullock, Allan (1991). «The Double Image», en Malcolm Bradbury y James McFarlane (eds.), Modernism. Londres: Penguin, pp. 58-70.

Cardwell, Richard y B. McGuirk, eds. (1993). ¿Qué es el modernismo? Nueva encuesta. Nuevas lecturas. Boulder: Society of Spanish and Spanish-American Studies.

Clarín (2009). Su único hijo. Madrid: Cátedra.

Correa, Gustavo (1977). Realidad, ficción y símbolo en las novelas de Pérez Galdós. Madrid: Gredos.

Fernández Sánchez-Alarcos, Raúl (1995). La novela modernista de Ángel Ganivet. Granada: Diputación de Granada.

Franz, Thomas (2002). Niebla inexplorada. Newark: Juan de la Cuesta.

Friedman, Edward H. (2006). Cervantes in the Middle. Realism and Reality in the Spanish Novel from Lazarillo de Tormes to Niebla. Newark: Juan de la Cuesta.

Ganivet, Ángel (1998). Los trabajos del infatigable creador Pío Cid. Madrid: Cátedra.

Garrido Ardila, J. A. (2008). «Nueva lectura de Niebla: Kierkegaard y el amor», Revista de Literatura. LXX, pp. 83-115.

Garrido Ardila, J. A. (2009). «Unamuno y el regeneracionismo», en Ana Chaguaceda (ed.), Unamuno: Estudios sobre su obra IV. Salamanca: Universidad de Salamanca, pp. 207234.

Garrido Ardila, J. A. (2010). «Unamuno y Cervantes: Narradores y narración en Niebla», Modern Language Notes. CXXXV, pp. 348-368.

Garrido Ardila, J. A. (2011a). «Amor y religión en San Manuel Bueno, mártir», Romance Quarterly. LVIII, 2, pp. 94-113.

Garrido Ardila, J. A. (2011b). «Cartografía de la novela digresiva en España», Symposium. LXVI, 3, pp. 207-227.

Garrido Ardila, J. A. (2011c). «The Origin of Unamuno's Mist: Unamuno's Copy of Kierkegaard's Diary of the Seducer», Modern Philology. CIX, 1, pp. 135-143.

Garrido Ardila, J. A. (2012a). «Unamuno, el monólogo interior y el flujo de conciencia: de William James y Amor y pedagogía a Knut Hamsun y Niebla», Hispanic Review. LXXX.3, pp. 445-466.

Garrido Ardila, J. A. (2012b). «Unamuno, Freud y Strindberg: los sueños en Amor y pedagogía y Niebla», Neophilologus. XCVI, 1, pp. 47-64.

Garrido Ardila, J. A. (2012c), «The Swedish Precursor of the Spanish esperpento: Strindberg's Spökesonaten and Valle-Inclán's Luces de Bohemia», Revue de Littérature compare. LXXXVI, 3, pp. 283-301.

Garrido Ardila, J. A. (2013a). «Prólogo», en Pío Baroja, Camino de perfección. Madrid: Alianza. 
Garrido Ardila, J. A. (2013b). «El monólogo interior en las novelas espiritualistas de Pardo Bazán, Clarín y Galdós (1889-1895)», Boletín de la Real Academia Española. XCIII.

Gullón, Germán (2003). El jardín interior de la burguesía. La novela moderna en España (1885-1902). Madrid: Biblioteca Nueva.

Gullón, Germán (2006). La modernidad silenciada. La cultura española en torno a 1900. Madrid: Biblioteca Nueva.

Gullón, Germán (2007). «Introducción», en Benito Pérez Galdós, La desheredada. Madrid: Cátedra, pp. 9-46.

Gullón, Ricardo (1969). La invención del 98 y otros ensayos. Madrid: Gredos.

Gullón, Ricardo (1971). Direcciones del Modernismo. Madrid: Gredos.

Herrero, Javier (1966). «El elemento biográfico en Los trabajos del infatigable creador Pío Cid», Hispanic Review. XXXIV, pp. 95-110.

Hoyle, Alan (2000). «Introduction: The Intellectual Debate», en Joseph Harrison y Alan Hoyle (eds.), Spain's 1898 Crisis. Regenerationism, Modernism, Post-Colonialism. Manchester y Nueva York: Manchester University Press, pp. 9-53.

James, David (2010). «Modernist Narratives. Revisions and Rereadings», en Peter Brooker et al, The Oxford Handbook of Modernisms. Oxford: Oxford University Press, pp. 85-107.

Jiménez Morales, María Isabel (2008). «Emilia Pardo Bazán, cronista en París (1889)», Revista de Literatura. LXX, 140, pp. 507-532.

Johnson, Roberta (1993). Crossfire. Philosophy and the Novel in Spain, 1900-193. Lexington: The University Press of Kentucky.

Johnson, Roberta (2003). Gender and Nation in the Spanish Modernist Novel. Nashville: Vanderbilt University Press.

Johnson, Roberta (2010). «Spanish Feminist Thought of the Modern Era», Anales de la Literatura Española Contemporánea. XXXV, 1, pp. 35-62.

Kirkpatrick, Susan (2003). Mujer, modernismo y vanguardia en España (1898-1931). Madrid: Cátedra.

Kronik, John W. (1974). «Estructuras dinámicas en Nazarín», Anales Galdosianos. IX, pp. 81-98.

Longhurst, C. A. (1977). Critical Guide to El mundo es ansí. Londres: Grant and Cutler.

Longhurst, C. A. (1992). «Camino de perfección and the Modernist Aesthetic», en Ann L. Mackenzie y Dorothy S. Severin (eds.), Hispanic Studies in Honour of Geoffrey Ribbans. Liverpool: Liverpool University Press, pp. 191-203.

Longhurst, C. A. (1999). «The Turn of the Novel in Spain. From Realism to Modernism in Spanish Fition», en Anthony Clark (ed.), A Further Range. Studies in Spanish Literature from Galdós to Unamuno. Exeter: Exeter University Press, pp. 1-43.

Longhurst, C. A. (2000a). «Noventaiocho y novela: lo viejo y lo nuevo», en Joseph Harrison y Alan Hoyle, Spain's 1898 Crisis. Manchester: Manchester University Press, pp. 170180 .

Longhurst, C. A. (2000b). «Ruptures of Continuity: From Realism to Modernism and the Avant-Garde», en Francis Lough (ed.), Hacia la novela nueva. Essays on the Spanish Avant-Garde Novel. Berna: Peter Lang, pp. 19-42.

López, Mariano (1978). «Antinaturalismo y humanismo en Galdós: Ángel Guerra, Nazarín y Halma», Hispania. LXI, pp. 69-77.

Macklin, John (1983). «The Modernist Mind: Identity and Integration in Pío Baroja's $\mathrm{Ca}$ mino de perfección», Neophilologus. LXVII, pp. 540-455.

Macklin, John (1993). «Competing Voices: Unamuno's Niebla and the Discourse of Modernism», en M. A. Rees (ed.), After Cervantes: 75 Years of Iberian Studies at Leeds. Leeds: Trinity and All Saints College, pp. 167-193. 
Mainer, José-Carlos (1986). La Edad de Plata (1902-1939). Ensayo de interpretación de un proceso cultural. Madrid: Cátedra.

Mainer, José-Carlos, ed. (2010). Modernidad y nacionalismo 1900-1939. Barcelona: Crítica.

Martínez Martínez, Francisco José (ed.) (2003). Las novelas de 1902. Madrid: Biblioteca Nueva.

Matz, Jesse (2008). «The Novel», en David Bradshaw y Kevin J. H. Dettmar (eds.), A Companion to Modernist Literature and Culture. Nueva York: Wiley-Blackwell, pp. 215226.

Moral, Carmen del (1974). La sociedad madrileña de fin de siglo y Baroja. Madrid: Turner.

Oleza, Juan (1988). «Su único hijo versus La Regenta: una clave espiritualista», en Yvan Lissorgues (ed.), Realismo y Naturalismo en España en la segunda mitad del siglo XIX. Barcelona: Anthropos, pp. 421-444.

Oleza, Juan (1989). «Su único hijo y la disolución de la fábrica naturalista», Ínsula. DXIV, pp. $27-28$.

Ortega y Gasset, José (1969). Meditaciones del Quijote e Ideas sobre la novela. Madrid: Espasa-Calpe.

Øveraas, Anne Marie (1993). Nivola contra novela. Salamanca: Ediciones Universidad de Salamanca.

Palley, Julian (1968). «Nazarín y El idiota», Ínsula, 258, p. 3.

Rivkin, Laura (1986). «Los trabajos del infatigable creador Pío Cid: hacia una estética simbolista», en Miguel Ángel Garrido Gallardo (ed.), Crítica semiológica de textos hispánicos. Madrid: CSIC, pp. 335-342.

Romero López, Dolores (1998). Una relectura del Fin de Siglo en el marco de la literatura comparada: teoría y praxis. Berna: Peter Lang.

Sackett, Theodore Alan (2001). «'Galdosismo' and Modernism in Ganivet's Los trabajos del infatigable creador Pío Cid», Anales Galdosianos. Homenaje a John W. Kronik. XXXVI, pp. 243-254.

Salgado, María A. (1997). «Pío Cid soy yo: Mito/auto/biografía de Ángel Ganivet«, RILCE. XIII, 2, pp. 223-242.

Santiáñez, Nil (1996). «Poéticas del modernismo. Espíritu lúdico y juegos de lenguaje en La incógnita 1889», Modern Language Notes. CXI, 2, pp. 299-326.

Santiáñez, Nil (2002). Investigaciones literarias. Modernidad, historia de la literatura y modernismos. Barcelona: Crítica.

Santiáñez, Nil (2004). «Great Masters of Spanish Modernism«, en David T. Gies (ed.), The Cambridge History of Spanish Literature. Cambridge: Cambridge University Press, pp. 479-499.

Santiáñez-Tió, Nil (1994). Ángel Ganivet, escritor modernista. Teoría y novela en el fin de siglo español. Madrid: Gredos.

Shaw, Donald (2010). «Hispanic Literature and Modernism», en Peter Brooker et al (eds.), The Oxford Handbook of Modernisms. Oxford: Oxford University Press, pp. 896-909.

Smith, Stan (1994). The Origins of Modernism. Eliot, Pound, Yeats and the Rhetorics of Renewal. Hemel Hempstead: Harvester Wheatsheaf.

Soufas, C. Christopher, Jr. (2010). «Modernism and Spain: Spanish Criticism at the Crossroads». Anales de la Literatura Española Contemporánea. XXXV, 1, pp. 7-16.

Soufas, Christopher (2007). The Subject in Question: Early contemporary Spanish Literature and Modernism. Washington DC: Catholic University of America.

Spires, Robert (1988). Transparent Simulacra. Spanish Fiction 1902-1926. Columbia: Missouri University Press.

Unamuno, Miguel de (1999). Paz en la guerra. Madrid: Cátedra.

Unamuno, Miguel de (2007). Amor y pedagogía. Madrid: Espasa-Calpe. 
Valis, Noël (1981). The Decadent Vision in Leopoldo Alas. Baton Rouge y Londres: Louisiana State University.

Vauthier, Bénédicte (1999). Niebla de Miguel de Unamuno: a favor de Cervantes, en contra de los «cervantófilos». Estudio de narratología estilística. Nueva York: Peter Lang.

Villanueva Prieto, Darío (2005). Valle-Inclán, novelista del modernismo. Valencia: Tirant lo Blanch.

Zavala, Iris (1991). La posmodernidad y Mijail Bajtín. Una poética dialógica. Madrid: Espasa-Calpe.

Mayoral, Marina (1987). «Introducción», en Emilia Pardo Bazán, Insolación. Madrid: EspasaCalpe, pp. 9-36.

Santiáñez, Nil (1989). «Una marquesita sandunguera, o el mito del naturalismo en Insolación», Revista de Estudios Hispánicos. XXIII, 2, pp. 119-134.

Fecha de recepción: 21 de enero de 2011

Fecha de aceptación: 9 de septiembre de 2011 